\title{
Political Economy in a Lunar Colony: A Simulation of the Relationship Between Technology and Politics
}

\author{
Daniel McIntosh, Kiev-Mohyla Academy
}

In the spring semester of 1990 , a class was organized and conducted at New College of the University of South Florida as an experiment in political science education. The centerpiece was the simulation of a lunar colony in a mainframe computer at the University of Northern Arizona (NAU). Students used their personal computers, which were connected to the local university mainframe via modem, to connect through Internet to NAU. They interacted with one another and with the student members of artificial societies created at several other schools. Taken as a whole, the NAU Solar System Simulation, as it is known, is an example of the promise and limits of computermediated interaction for political science instruction.

The simulation was developed as an outgrowth of the CONTACT conference. In CONTACT, social scientists, science fiction authors, engineers, and other interested experts came together to design a society of the mid twenty-first century. In the solar system simulation, managed by professors Reed D. Riner and Melvin K. Neville of the University of Northern Arizona, the participants are students from high school to graduate school. When New College joined, the teams included simulations of an arcology in the southwestern United States, an undersea base operated near the Arctic circle, an orbital habitat at the point of gravitational balance of the earth-moon system, an expedition to colonize Mars, and a colony constructed below the surface of the moon.

At that time, the New College team was the only political science class participating in the project. Outside the simulation, I operated like any other instructor: giving assignments, leading discussions, and evaluating student work. Inside the simulation, I stepped aside to allow students to design, and function in, their own world. Participation went far beyond my expectations. By the middle of the semester, students were accessing the simulation, alone and in groups, so often that some needed to be reminded to make time for their other classes.

... the NAU Solar

System Simulation, as it is known, is an example of the promise and limits of computer-mediated interaction for political science instruction.

Students were recruited by posters and by word of mouth. They included majors in political science, history, biology, physics, economics, and literature. There were a dozen members in the class, predominantly freshmen and sophomores, and each specialized in a functional area related to his or her interests. Thus, one biology major researched space medicine and developed the health care system. Another student focused on life support and ecology. A student in the hard sciences reviewed NASA publications on lunar construction in order to set the engineering parameters of the colony. The economics student focused on intercolony trade and trade negotiations, while the English major negotiated with other colonies to specify the history of the colony and the solar system as a whole. Political science majors specialized in communications, public administration, internal security, and foreign affairs. The class as a whole, in their roles as citizens of the new society, had to work together to settle constitutional questions.

In the early weeks, each student worked as an individual to become expert in his or her particular field. Simultaneously, the class as a whole began by working backwards from science fiction novels and films to articulate the assumptions found in those works. This helped the students to articulate their own assumptions.

Next, the assumptions of the CONTACT project and solar system simulation were specified. The year was announced to be 2060 . It was assumed no global war had occurred. States and international organizations were significant political actors, as were multinational corporations. Space travel had progressed to the point that a trip from the earth to the moon was comparable to intercontinental air travel today. Conflict between rich and poor was reflected in a split between "spacegoing" and "earthbound" communities, while among the spacegoing powers there were disagreements on trade and property rights. No major breakthroughs in physics were projected, nor was progress in nanotechnology. In short, the assumptions were conservative, so students would not flounder in the "whatifs" of simultaneous technological revolutions.

Next for the New College Luna Team came readings in political science. As the class as a whole used this common reading list, the student specialists worked independently to develop guides to their areas of interest for use by other students. Along the way, they compared notes in class concerning the direction their designs and research were taking them. This, in turn, required negotiation (and occasional arbitration by the instructor) concerning how to integrate their plans. After one-third of the semester, the student research papers 
were completed and assembled to create a handbook on colony operations, which served as the technology baseline for political and economic decisions. This information was also passed on to a "board of virtual consultants": experts who would critique the simulation and participate in it.

The next task was to write a constitution for the colony. The class produced a libertarian document based on the U.S. Constitution. But they quickly began to see how the problems of living together in a harsh artificial environment had political consequences. Topics that generated the best discussions in this section included: Can children choose to opt out of the social contract made by their parents? Is access to air a fundamental right? What limits will be placed on the authority of security or health officials to safeguard the colony at the expense of individual privacy?

The civil liberties problem was made more difficult by a technical innovation incorporated by the students into the colony handbook. Each citizen of the colony, it was agreed, would have a coded chip surgically embedded in one hand. This "key" helped to regulate access to family living areas and sensitive installations. As an afterthought, the chip was also linked to the colony's computerized financial network. Purchases and contracts could be registered simply by shaking hands. Children had a less powerful chip, while visitors had to make do with either a temporary hand-held card or the assistance of a resident.

The Luna colony was constructed in the computer at NAU and linked to other societies. A system-wide communications net simulated with text real-time conference calls in "virtual reality," as well as providing students and instructors with normal electronic mail. Setting agendas and meeting times, and, in particular, arranging to get representatives of several teams in conference simultaneously, proved to be difficult. There was never a single meeting involving representatives of all teams at once.

Once they had completed the construction phase, instructors made the teams' tasks more difficult by announcing a series of crises (for example, a catastrophic failure in the system used to produce food). The crises could be overcome through cooperation, and by applying the technologies already developed.

There were also some attempts to solve political-economic problems (such as trade relations) by means of new, "magical" technology. These attempts to produce unlimited power or slash travel times on a moments' notice were rejected by the team instructors. In addition, the Luna Team showed a clear preference for preplanned options. Even when the particular "garbage can" solution worked out previously was clearly not the best solution they could reach, there remained a desire to opt for the satisficing decision rather than reopen old debates.

Finally, the colony suffered a problem they had worked to avoid: growing authoritarianism. Acting to preserve order in crises, the colony's security specialist began to trace the use of the implanted keys. This gave him a record of where each citizen was at any given moment, and even permitted him access to purchases and bank records.

Members of the class found themselves subject to ever more arbitrary and invasive policies. Travel was restricted. Contingency plans were developed to lock off sections of the colony in case of emergency. Not only were doors and corridors to be sealed, but an option was developed to reduce oxygen available to people in "dangerous" sectors. These plans were never implemented, but the students were left with an understanding that their liberty was as fragile as their lives.

Creating a new world with the computer gave the class an opportunity to see for themselves how technology and politics can interact. It raised issues of basic political theory and practice. It encouraged student involvement and discussion. It also required extra effort by the instructor. The simulation will work only if the instructor maintains the distinction between his roles as teacher, observer, and referee. Computer-mediated realtime simulation is not without problems, but the experiment at New College is a demonstration of its potential. Perhaps the most encouraging sign of what was accomplished came the next year: students volunteered to work with the project again, even though no class had been organized.

This year, participating classes are connecting to the solar system simulation from the University of Dayton, University of Hawaii, University of Texas at Austin, Eastern Oregon State, and an honors high school class. More are in the process of joining. Faculty interested in learning more about the NAU Solar System Simulation may contact Reed Riner of the University of Northern Arizona (rdr@sunset.cse.nau.edu).

\footnotetext{
About the Author

Daniel McIntosh was an instructor at New College from 1989 to 1992 and at Wabash College in 1993. He is a visiting professor at the Kiev-Mohyla Academy (Kiev, Ukraine). Current research projects include intervention decision making in the Commonwealth of Independent States and the restructuring of post-Soviet space programs. He can be reached at danmcintosh@delphi.com.
} 